\title{
CISELexia: Computer-Based Method for Improving Self-Awareness in Children with Dyslexia
}

\author{
Aulia Rahmawati ${ }^{*}, 1$, Emil Robert Kaburuan ${ }^{2}$, Anditya Arifianto ${ }^{1}$, Nahda Kurnia Juniati ${ }^{3}$
}

${ }^{1}$ School of Computing, Telkom University, Bandung, Indonesia 40257

${ }^{2}$ Information System Management Department, BINUS Graduate Program - Master of Information System Management, Bina Nusantara University, Jakarta, Indonesia 11480

${ }^{3}$ Psychology, Informatics and Business University, Indonesia 40286

\section{A R T I C L E I N F O}

Article history:

Received: 30 July, 2019

Accepted: 13 September, 2019

Online: 08 October, 2019

Keywords:

Dyslexia

Emotional-intelligence

Self-awareness

Gamification

\begin{abstract}
A B S T R A C T
Dyslexia has a lack of ability which causes other disturbances to social-emotional development. Based on an interview with the Chair of the Indonesian Dyslexia Association, increasing self-awareness is one form of dyslexia therapy to reduce that problem. Therefore there is a need for increasing self-awareness to solve that problem, whereas such technology the closest has not been fit with dyslexic children need. Then this study tries to focus on designed and developed CISELexia (Computer-Based Method for Improving SelfAwareness in Children with Dyslexia) technology using a gamification approach. It aims to help dyslexic children improve their competencies by increasing their self-awareness. Based on the implementation results CISELexia can increase the child's self-awareness state according to the rubric questionnaire given for about $10 \%$.
\end{abstract}

\section{Introduction}

Dyslexia is a type of language disorder which further affects reading, writing, spelling, and organizational skills. Early diagnosis of dyslexia involves disruption to academic abilities, such as problems with reading, text comprehension, spelling, writing, counting, and mathematical reasoning. With this lack of ability, it can cause other disturbances to social-emotional development. Based on an interview with the Chair of the Indonesian Dyslexia Association, it was stated that dyslexic children have a tendency to make mistakes in understanding their emotions (Dewi K., 2017). Increasing self-awareness should solve that problem. Unfortunately, the closest technology available for social treatment has not been fit for the needs of dyslexic children.

Dyslexia cannot be cured, however, the symptom can be reduced. One of them is through therapy. And along with the development of technology, some technologies can help the process of this therapy such as the use of video, games, and movies [1-8]. The closest technologies that can overcome that problem are SIDES (Shared Interfaces to Develop Effective Social Skill), AVP (Authorable Virtual Peer), computer-presented social stories and video models. But, those technologies are

\footnotetext{
*Aulia Rahmawati., Email: auliasuwito@gmail.com
}

designed for autism child, which those has different characteristics with a dyslexic child. The lack of technology that can support therapy on social-emotional development, make an opportunity to start this research.

As previously mentioned, there is no cure for dyslexia, then one of the solutions that have been offered by researchers was providing therapy to treat people with dyslexia. This therapy is usually done by a professional in a clinic-based session. But along with the development of technology, various ways can help the process of this therapy such as the use of video, games, and movies [1-8]. One of the technologies that support the therapy of academic skills in dyslexia is Lexipal. Lexipal is a technology that uses multisensory approach combined with gamification approach to build "learn-to-read" therapy for children with dyslexia. The advantage of this technology is that Lexipal is made to meet the needs of Indonesian users. So, it can be accepted by users in Indonesia. The development of this technology has been adapted to some aspects of academic skills such as reading, writing, and counting [8].

Several examples of proven technologies which can be used in social skills improvement therapy are SIDES, AVP, computerpresented social stories and video models [9-13]. 


\section{R. Aulia et al. / Advances in Science, Technology and Engineering Systems Journal Vol. 4, No. 5, 258-267 (2019)}

Some of the technologies mentioned earlier, such as Lexipal and SIDES use game-based concepts as its core. This proves that game technology has the advantage of enhancing the treatment $[2$, $3,6,8,10]$. The same thing also revealed by some researchers that there is game technology that is used to help dyslexic children such as iLearnRW, Dyslexia Baca and Dyseggxia $[2,3,6]$. Those products are the examples of using gamification approach in developing dyslexia applications. Gamification is using game elements in non-game context purposes. Like Lexipal, Dyseggxia, Dyslexia Baca and iLearnRW which use game elements to build their application for learning purposes.

Based on the existing problems where the lack of technologysupported therapy for social-emotional development, this research tries to design and develop a technology to help dyslexic children to increase their self-awareness. The technology that will be designed and developed is CISELexia (Computer-Based Method for Improving Self-Awareness in Children with Dyslexia) which uses gamification approach and child-centered designed method to help develop the system that is by the stages of social-emotional development and dyslexic children needs.

\section{Related Works}

\subsection{Theory of Dyslexia}

Some references have mentioned the characteristics of dyslexia, including the American Psychiatric Association, International Dyslexia Association, Cuschieri, Solek, Marshall and Pennington. The American Psychiatric Association and the International Dyslexia Association describe the characteristics of specific learning difficulties, types of specific learning difficulties and diagnostic criteria for specific learning difficulties. On the other hand, Abigail Marshall describes dyslexia difficulties, how to teach dyslexic children and how to overcome the educational, personal and social problems. The difficulties that present in dyslexia sufferers are:

1. Inaccurate or slow word reading

2. Difficulty in understanding the meaning of the text

3. Difficulty in spelling

4. Difficulty in writing the expression

5. Difficulty in mastering numerical sense, number fact or calculation

6. Difficulty in mathematical reasoning

A person with dyslexia has normal or above-average intelligence. Dyslexia affects not only academically but also daily life aspects, one of which is emotional intelligence. Studies from [14] resulted that behavioral disorders and social problems occur more in dyslexic children than in non-dyslexic children. Several studies have shown that children with learning disabilities show higher aggression and misbehavior [15]. This shows that they have low emotional intelligence. [16] describes emotional intelligence: "Emotional intelligence is the ability to perceive emotions, to access and generate emotions to assist thought, to understand emotions and emotional knowledge, and to reflectively regulate emotions to promote emotional and intellectual growth."

This emotional intelligence is one of success indicators in social-emotional development. Emotional intelligence is one of the factors that influences social-emotional development. A study says that dyslexic children have social-emotional problem because of the relatively low level of emotional intelligence [17].

Daniel Goleman describes the five components of emotional intelligence:

1. Self-awareness

2. Self-regulation

3. Internal motivation

4. Empathy

5. Social competence

Self-awareness is the ability to recognize and understand moods, emotions and personal impulses, and their influence on others. Social emotions depend on the ability of self-awareness to monitor the emotional state and identify to name that emotion.

Self-awareness includes the ability [18]:

1. Emotional self-awareness

Recognizing one's emotion and their effects

2. Accurate self-assessment

Knowing one's strengths and limits

3. Self-Confidence

A strong sense of one's self-worth and capabilities

\subsection{Dyslexia Treatment}

According to Goleman and Indigrow Child Development Center Indonesia (Goleman, 1996a), there are two treatments performed on dyslexia sufferer: academic and social treatment or known as a social-emotion treatment. Treatment is performed in early childhood or about five years old (preschool) for maximum results [20]. Previously treatment in dyslexic children done by professionals in clinic-based sessions. But now the technology has begun to be developed to support treatment in children with dyslexia $[1,2,11-13,3-10]$.

\subsubsection{Academic Treatment}

Academic treatment focuses on developing academic skills such as reading, writing, and counting. One of the technologies that support the therapy of academic skills in dyslexia is Lexipal. Lexipal is a technology that uses multisensory approach combined with gamification approach to build "learn-to-read" therapy in children with dyslexia. The development of this technology has been adapted to some aspects of academic skills such as reading, writing, and counting [8]. Other technologies that support academic treatment are Dyslexia Baca and Dyseggxia [3, $6]$.

\subsubsection{Social Treatment}

Social-emotion treatment focuses on other skills that support social skills improvement. According to Goleman (Goleman, 1996a), social-emotion has several competencies that begin with self-awareness, self-regulation, motivation, empathy and social competence. Social competence is the highest stage in social skill, that is all forms of skill involving social behavior.

Since this study focuses on self-awareness, there are three competencies in self-awareness: emotional self-awareness, accurate self-assessment, and self-confidence [18]. From that competency, this research, indicators divided into five representing self-awareness ability. The indicators are: 


\section{R. Aulia et al. / Advances in Science, Technology and Engineering Systems Journal Vol. 4, No. 5, 258-267 (2019)}

1. Know yourself

This indicator represents how much we know about selfidentity such as name, date of birth, age and class.

2. Know your family

This indicator represents how much we know about our families like the names of parents, the number of brothers, the number of sisters, and their names.

3. Know your strengths

This indicator represents how much we know about our strengths. This research uses soft and academic skills for representing it.

4. Know your weakness

This indicator represents how much we know about our weaknesses. This research uses soft and academic skills for representing it.

\section{Know your emotion}

This indicator represents how much we know and understand each other's emotions and ourselves. Emotions that need to be mastered according to Daniel Goleman are categorized into eight emotions, they are anger, sadness, fear, happy, love, shock, annoyed and shame. Treatment on this indicator is done by studying the emotions of the other through pictures or videos of social situations.

\subsubsection{Existing Social Treatment}

According to observation in Indigrow Child Development Center, the existing social treatment is done by viewing social stories using video, then the child is asked to respond to what happened in the video. Psychologists also provide some questions related to the social situation based on the video. According to psychologists, within three months the children have been increasing self-awareness skills.

While there is no special assessment conducted to find out the self-awareness of children. Existing assessment is done only based on observations from the interactions between psychologists and children.

\subsection{Previous Works}

Some technologies have proven to improve social skills such as SIDES and AVP [9-13]. SIDES (Shared Interfaces to Develop Effective Social Skill) is a technology designed to assist Asperger's syndrome in training group work skills. This technology has form as tabletop computer games that contain case studies to solve in groups with the aim support effective group work created. It involves highly visual and uses cards, pattern building, and puzzle-solving as game mechanics. They say that cooperative computer games are effective to teach group work skills [10]. There is also an Authorable Virtual Peer (AVP), a technology that helps children learn to interact with each other in order to improve social skills through learning to interact with virtual peers. This technology is designed using a shared reality concept, dialogue, and simulation as game mechanics. It is addressed for autism spectrum disorders that have peer social interaction problems. AVP provides a lesson on how to interact with peers [13]. Another technology is by using computerpresented social stories and video models can have a positive effect on teaching the social skills of children with autism syndrome. They use social stories and video models to make an intervention on children with autism [12].

\subsection{Theory of Gamification}

The gamification approach is the concept of using game elements in a non-gaming context to improve user experience, learning, problem-solving, motivation and user engagement. The examples of non-gaming contexts are marketing, politics, education, health, and fitness. Using gamification can be a solution to achieve excellent training goals. This is proven by the use of gamification in game-based learning in some previous research [21-25]. To achieve those goals, it is necessary to know the game elements that are capable of supporting three dimensions of learning: cognitive, emotional and social [26-28].

In the cognitive area, gamification can use challenges tailored to player skills. In the emotional area, it involves the emotion of the user, how the gamification can trigger user emotions such as joy, curiosity, and frustration. And in the social area, gamification can provide a social experience like experience in new identities and roles, so the user can make a decision according to point of view [27].

One example of the use of the gamification approach in dyslexia treatment is Lexipal. Lexipal uses some game elements such as story, level, point, reward, and achievement. The use of gamification in Lexipal is for increasing motivation in learning [8]. The other examples are iLearnRW, Dyslexia Baca and Dyseggxia $[2,3,6]$.

\section{System Design}

\subsection{Application Design}

The design of CISELexia application is tailored to the characteristics of dyslexic children. Some of the characters of dyslexic children which are considered to make application design including:

1. Difficulty in spelling letters.

2. Difficulty in making written work such as essays.

3. Poor memory.

4. Difficulty in understanding sentences that are read or heard.

5. When listening to something, the attention span is short.

6. Difficulty in remembering names.

7. Difficulty in visual discrimination.

Based on research on the characteristics of dyslexic children, the results of the CISELexia application interface plan are as described in the following points.

\section{Main menu Scene}

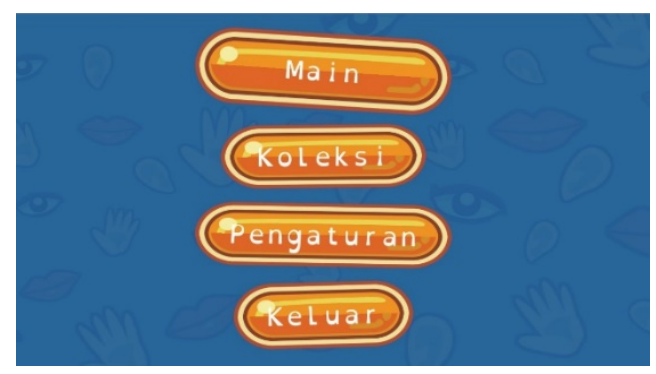

Figure 1: Main Menu Scene 
In the main menu scene, the menu buttons are arranged vertically. The play button is made larger than the other buttons to attract the attention of children to try it first.

\section{Home Scene}

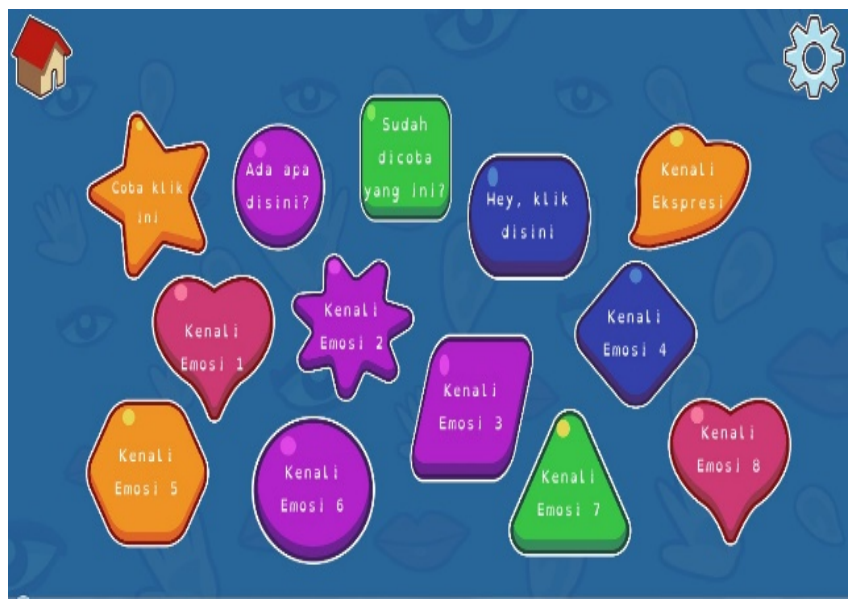

Figure 2: Home Scene

Before the children can start trying out the existing tasks, the children are introduced first to each character that appears on the task so that they can easily follow the storyline. Dyslexic children sometimes have difficulty in visual discrimination, so the buttons to start the task are made in various shapes and colors with the aim of introducing various shapes to the children. Compared to giving the task name to the text button, the text button contains a sentence that makes the children curious and want to press the button. The font used in CISELexia also uses a special font adapted to dyslexic children, namely OpenDyslexic font. The placement of the home button is on the upper left side and the settings button on the upper right side. The placement of these two buttons is consistent in all scenes, so this makes it easy for the children.

\section{Know Yourself and Know Your Family Scene}

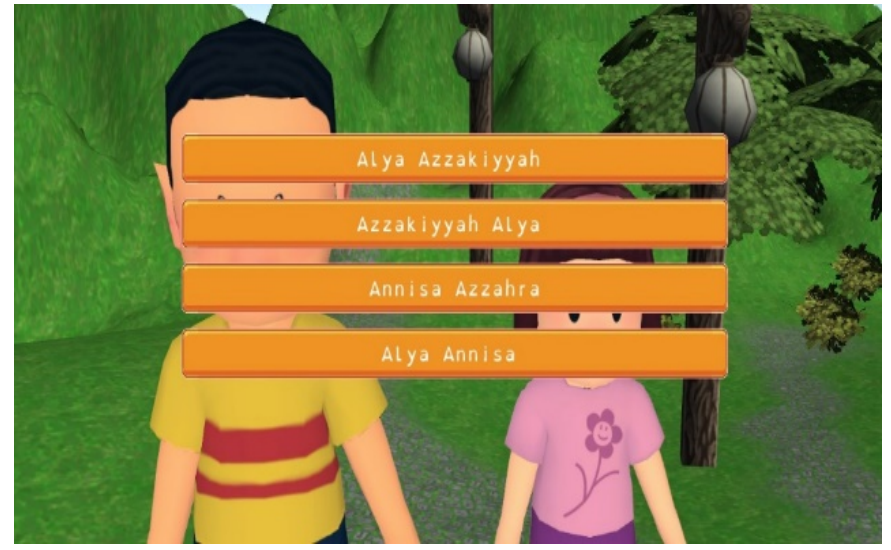

Figure 3: Example of Know Yourself/Family Scene

When the children press a button that leads to the know yourself or know your family scene, a video will appear describing the condition of the social situation with a narrative that can explore the children's identities and family through questions that appear in the middle of the video. Random choices are used to avoid children memorizing the pattern of question and answer.

\section{Know Your Strength and Know Your Weakness Scene}

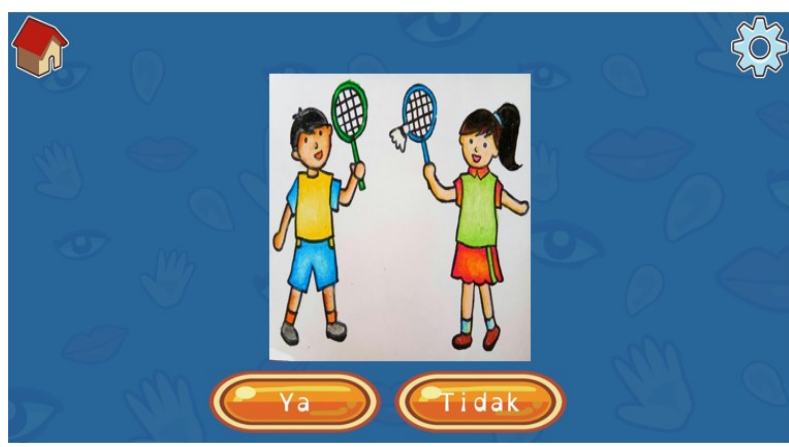

Figure 4: Example of Know Your Strength/Weakness Scene

Know your strength and know your weakness scene, the system provides a list of images about academic skills, sports, art, and daily activities. Furthermore, the child is asked to choose images according to their strength and their weaknesses.

Know Your Emotion Scene

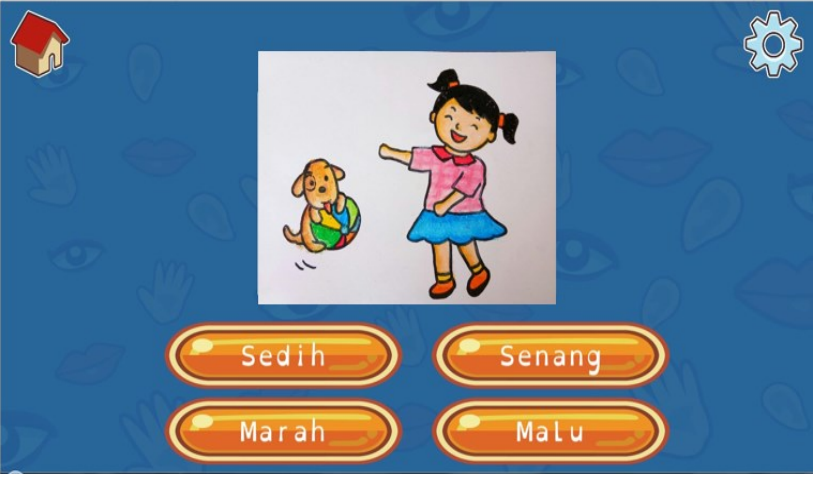

Figure 5: Example of Know Your Emotion Scene (First Figure)

The design of this scene is divided into two. The first scene is for emotion identification through images, see figure 5 and the second is emotion identification through video, see figure 6 . The video scene is almost similar to the know yourself and know your family scene. That is when the children press the button that leads to this scene, a short animated video will appear and at the end of the video, there are some questions about emotions shown by the characters. Animated videos are made in short duration to overcome the short attention span of the children. Random choice is used to avoid children memorizing the pattern of question and answer.

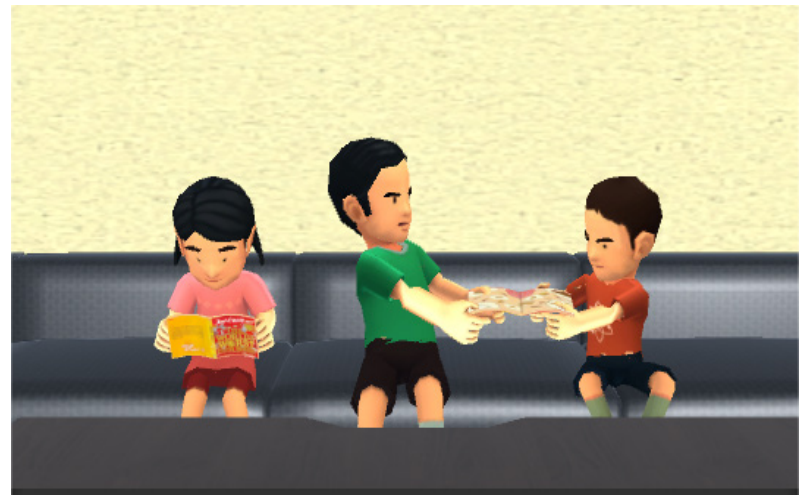

Figure 6: Example of Know Your Emotion Scene (Second Figure) 


\subsection{Video Content Generation}

This video content is made to know yourself, know your family and know your emotion indicators. For now, yourself and know your family indicators, the use of video is intended to create a social situation that can help children to recognize themselves and their families. While for the know your emotion indicator, the video is intended to help children understand emotions in everyday social situations. Narratives for video content is made so that it does not cause misperception in understanding emotions. One example of the narrative is as follows.

\section{Example 1:}

"That morning, I, my sister and my brother were reading a book in the living room. We read different books. 'Sis, can I borrow the book?' said my brother, pointing at the book held by my sister. 'No you can't, I am still reading it,' replied my sister.

Because it is not lent, my brother immediately seizes that book and then tore it. My sister looked at my brother cynically."

\section{Example 2:}

"It was already 6:00 in the morning. My mother screamed to wake me up. 'Andy wakes up, it's already 6 o'clock, you will be late for school.' But because I was still sleepy, I didn't respond to my mother's call and continued to sleep. The time showed 06:30, my mother screamed louder and began to go to my room.

'Son wake up quickly!!', My mother's voice was louder and she tried to shake my body. Then I woke up. I woke up lazily. 'Wake up kid, it's too late! Your pickup bus has departed! You must be late for school."'

The psychologist said that two examples above are narratives that can be used on video content for your know emotion indicator. But for example 2 is an example of an unfavorable narrative for emotional video content because it contains ambiguous emotions, that is, the mother's emotions being angry because the brother/sister who is late getting up and the mother's emotions being sad because the shuttle bus has departed. The narratives must pass an evaluation process from a psychologist to get video content that is appropriate for the target audiences.

The expected video results are far from multiple perceptions. So that in this research, we use 3D technology that will make it easy to set the camera to get the right viewpoint, so multiple perceptions video can be avoided.

\subsection{Character Design}

In making the characters for video content, this study utilizes 3D technology. The character formed is also adjusted to the characteristics of children with dyslexia. That is by creating unique characters, easily recognizable and unambiguous. Such as the use of hijab or skirt to depict female characters, and used shorts with short haircuts to depict male characters.
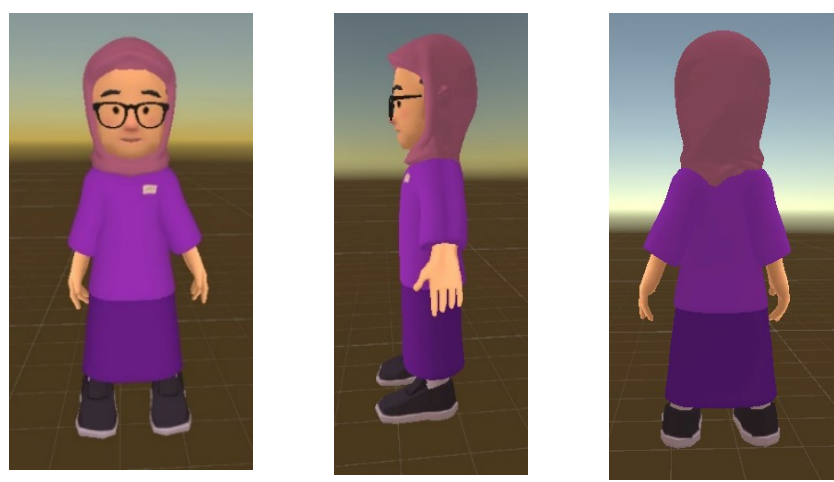

Figure 7: Example of female characters (Teacher)

\subsection{Task Generation}

Based on the background of this research, CISELexia was proposed as the technology solution to improve self-awareness. Thus CISELexia is designed based on indicators in self-awareness. This indicator is used as a parameter for measuring self-awareness increase. The indicator can be seen in figure 8 .

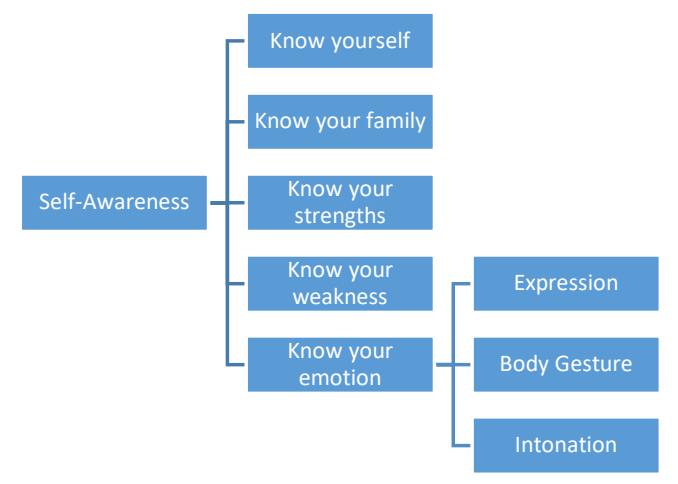

Figure 8: Indicators of Self-Awareness

Based on existing indicators, the tasks are made on the CISELexia system that represents each indicator. The tasks which are developed in the CISELexia application are adapted to the indicators that will be achieved based on self-awareness theories which have been studied previously. This task is divided into 7 types and represents 5 indicators, can be seen in Table 1 for more details.

Table 1: Mapping Table for Tasks with Indicators

\begin{tabular}{|c|c|c|c|c|c|}
\hline & $\begin{array}{c}\text { Know } \\
\text { yourself }\end{array}$ & $\begin{array}{c}\text { Know your } \\
\text { family }\end{array}$ & $\begin{array}{c}\text { Know your } \\
\text { strength }\end{array}$ & $\begin{array}{c}\text { Know your } \\
\text { weakness }\end{array}$ & $\begin{array}{c}\text { Know your } \\
\text { emotion }\end{array}$ \\
\hline Task 1 & $\sqrt{ }$ & & & & \\
\hline Task 2 & & $\sqrt{ }$ & & & \\
\hline Task 3 & & & $\sqrt{ }$ & & \\
\hline Task 4 & & & & $\sqrt{ }$ & \\
\hline Task 5 & & & & & $\sqrt{ }$ \\
\hline Task 6 & & & & & $\sqrt{ }$ \\
\hline Task 7 & & & & & $\sqrt{ }$ \\
\hline
\end{tabular}

- Know yourself

For know yourself indicator, it will be accommodated by task 1 , where there are dialogue and some exercises in the form of questions about identity such as name, age, and class. 
- Know your family

This indicator will be accommodated by task 2, by displaying a dialogue in the form of a social situation which involves exercises in the form of questions about our family, such as the names of parents, the number of brothers and the number of sisters.

- Know your strengths

This indicator will be accommodated by task 3 , the system will provide various types of strength and the user will choose the strength that suits him. Where types of strength are used based on soft and academic skills.

- Know your weakness

This indicator will be accommodated by task 4, the system will provide various types of weakness and the user will choose the weakness that suit him. Where types of strength are used based on soft and academic skills.

\section{- Know your emotion}

These indicators will be divided into three tasks that are accommodated by task 5, 6 and 7. In task 5 the system provides various images of the social situation for analyzed by the user and what should we do. In tasks 6 and 7 system provided a social story in the form of video and then the user will be asked to answer the question that displayed.

Each training task has its own game mechanics with the following details:

1. Task $1-2$

Game mechanics in these tasks is a social story with the visual novel game model, which is a game with a fiction interaction game featuring a story and comes with a conversation as a narrative (dialogue) of each character. Among the dialogues that occur between actors, will be available questions that must be answered by the user as an assessment process on the indicator.

2. Task 3-4

Game mechanics in these tasks is that the application provides some choices that represent strength and weakness, then the user must choose some choices that represent themselves.

3. Task 5-7

Game mechanics in these tasks is almost similar to tasks 1-2 which is the visual novel model. The difference between them is the question of the assessment process. In this task, the user is asked to understand and analyze the social situation that occurred. So that the user will understand the emotions of the characters that exist in the situation, hope the user can answer the question that posed.

The whole question in the task is multiple choice. The system provides answer options, so the user only needs to choose the right answer, the user does not need to type their answer.

\subsection{The Use of Gamification Approach}

In order for CISELexia could be used to intervene in increasing self-awareness capabilities, the gamification approach is inserted in the application. The gamification approach is the concept of using elements of game design in a non-gaming context to improve user experience, learning, problem-solving, motivation and user engagement. Gamification on the CISELexia application can be seen from the scores, stars, and feedback. The use of score and star systems can be seen in figure 9 . With the score, the system can trigger children to always increase score in each application usage. While the use of feedback is in the voice form at the end of the answering process. The feedback system can also be used to trigger children to find out their mistakes and try to fix them.



Figure 9: Example of Score and Star Systems

\subsection{Scoring System}

The assessment used in the CISELexia system is divided into two types. The first, for know yourself, know your family and know your emotion indicators using the formula on equation 1.

$$
\text { score }=\frac{\text { number of correct answers }}{\text { number of questions }}
$$

The second, know your strength and know your weakness indicators using the formula on equation 2 .

$$
\text { score }=\left\{\begin{array}{l}
0, \text { if } B^{\prime} \cap A \\
1, \text { if } A^{\prime} \cap B \\
2, \text { if } A \cap B
\end{array}\right.
$$

With is a strength/weakness list based on parents or psychologists assessment and is a strength/weakness list based on the child's answer.

\section{Implementation and Result}

\subsection{Implementations}

This implementation was carried out by dyslexic children along with their psychologists. Children will be asked to use the system as a form of exercise in recognizing self-awareness abilities, while psychologists are asked to review children's selfawareness abilities before using the system and after using the system during certain intervals.

\subsubsection{Implementation Objective}

In accordance with the objectives of the research mentioned earlier that this study aims to investigate the effect of using technology in order to support dyslexic children in improving self-awareness. Therefore, in this implementation, the historical record of the children was made when they use the system.

\subsubsection{Implementation Strategy}

The implementation strategy carried out in this study was doing test in dyslexic children with one-month intervals, the use of the system was done once a week. In addition, in order to be able to answer the hypothesis in this study, a questionnaire was taken using the pre-test and post-test rubric by the psychologist to 
see the child's self-awareness abilities before and after using the application.

The initial implementation in this study was conducted by collecting personal data of children identified with dyslexia with an age range of 7-13 years. The initial implementation was carried out on five dyslexic children.

This child's personal data will be used as the child's answer validation when using the CISELexia system. In addition, in this study, there are also three other types of data, namely pre-test data, answer data, and post-test data.

Pre-test data is an individual respondent's personal review data on self-awareness ability before using the CISELexia system. This data is obtained from a children's self-awareness rubric questionnaire. The answer data is the respondent's historical data taken from a collection of individual answers while using the CISELexia system. The post-test data is the respondent's individual personal review data on self-awareness aspects after using the CISELexia system. This data is also obtained from children's self-awareness rubric questionnaire.

In order to achieve the objectives of the research, the strategy carried out in this implementation is to test the CISELexia system for chosen respondents during certain intervals. In this implementation, it was carried out in 1-month intervals with 1 use each week. Then the results of changes from respondents who use the system compared with the average time needed by respondents to be able to achieve changes in the aspect of selfawareness with a model without a system.

\subsection{Implementation result}

Based on the implementation results obtained data of a child's self-awareness conditions from a psychologist before application usage (pre-test), during the application usage (1st-obs, 2nd-obs, 3rd-obs, and 4th-obs) and data of child's self-awareness conditions from a psychologist after application usage (post-test). From this data, the data were categorized into 5 indicators, know yourself, know your family, know your strength, know your weakness and know your emotion. The range of values used in this data is $0-1$. With a value close to 1 means the child is increasingly mastering the indicator.

The implementation shows the average child has improved their self-awareness state based on the rubric questionnaire in this research. To see the whole result of the implementation, it can be seen in table 2.

Table 2: Average score of self-awareness indicators in whole implementation result

\begin{tabular}{|c|c|c|c|c|c|c|}
\hline Indicators & $\begin{array}{c}\text { Pre-Test } \\
\text { (psychologist) }\end{array}$ & $\begin{array}{c}1 \text { st } \\
\text { Obs }\end{array}$ & $\begin{array}{c}\text { 2nd } \\
\text { Obs }\end{array}$ & $\begin{array}{c}\text { 3rd } \\
\text { Obs }\end{array}$ & $\begin{array}{c}4 \text { th } \\
\text { Obs }\end{array}$ & $\begin{array}{c}\text { Post-Test } \\
\text { (psychologist) }\end{array}$ \\
\hline $\begin{array}{c}\text { Know } \\
\text { yourself }\end{array}$ & 0.973 & 1 & 1 & 1 & 1 & 1 \\
\hline $\begin{array}{c}\text { Know your } \\
\text { family }\end{array}$ & 0.9 & 0.95 & 0.95 & 0.95 & 1 & 0.934 \\
\hline $\begin{array}{c}\text { Know your } \\
\text { strength }\end{array}$ & 0.4 & 0.546 & 0.619 & 0.673 & 0.728 & 0.6 \\
\hline $\begin{array}{c}\text { Know your } \\
\text { weakness }\end{array}$ & 0.4 & 0.291 & 0.364 & 0.4 & 0.51 & 0.6 \\
\hline $\begin{array}{c}\text { Know your } \\
\text { emotion }\end{array}$ & 0.668 & 0.756 & 0.834 & 0.934 & 0.967 & 0.734 \\
\hline Average & $\mathbf{0 . 6 6 8}$ & 0.709 & 0.753 & 0.791 & 0.841 & $\mathbf{0 . 7 7 4}$ \\
\hline
\end{tabular}

The results of the study show that the average child has mastered know yourself indicator. It was seen that the child was able to complete the task from the application. The data from the psychologist also stated the same thing that the children increase their score from 0.973 to 1 .

\section{Know Your Family Indicator}

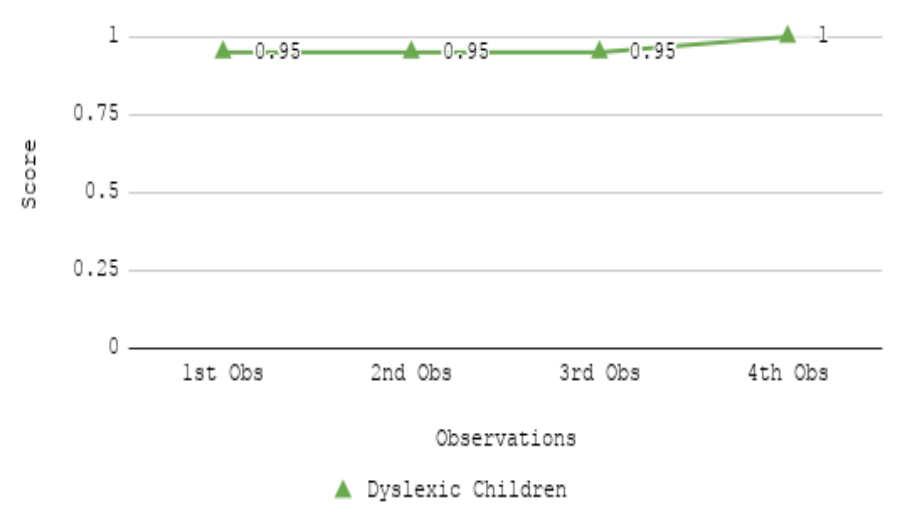

Figure 10: Average Results of Know Your Family Indicators Assessment

The average child has mastered this indicator. Seen at the end of the observation the child is able to complete all the tasks and this also shows an increase compared to previous observations. The same thing was also shown from psychologist data, which has increased from 0.9 to 0.93 . But even though, there are some children who are still having difficulty distinguishing siblings or not. That's why at the beginning of observation the values achieved are not perfect and the increased score from psychologists is low.

\section{Know Your Srength Indicator}

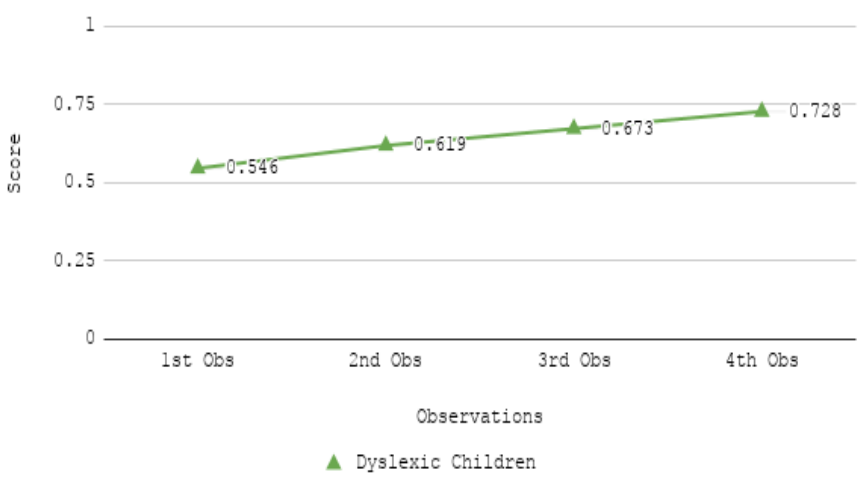

Figure 11: Average Results of Know Your Strength Indicators Assessment

Overall the know your strength indicator chart shows an increase during application usage. The results from the psychologist also showed an increase, based on table 2 that is from 0.4 to 0.6 . But in this case, the psychologist states that the child's ability to express his strength is quite difficult to master, thus causing a not too significant increase and some even constant, one of them can be seen in figure 12 . 


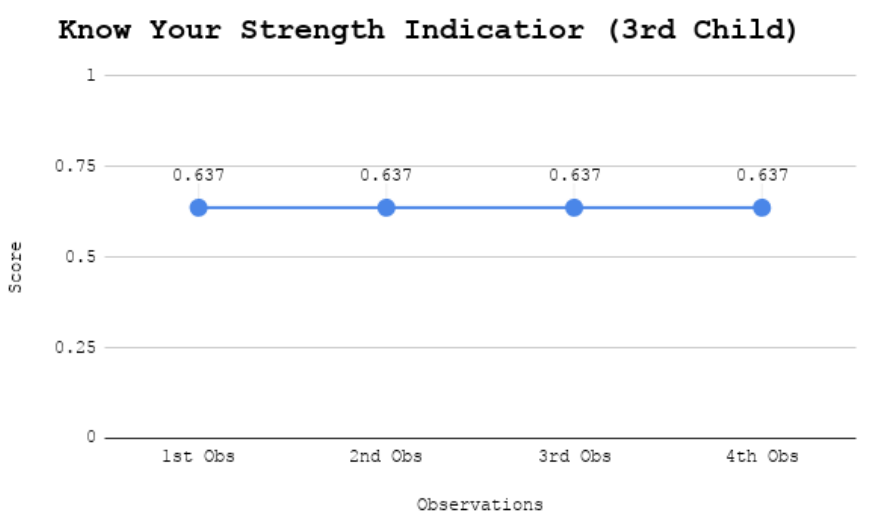

Figure 12: Assessment Result of Know Your Strength Indicator for 3rd Child

Above is an example of a child who does not give an increase in the know your strength indicator at each observation session. They are still inconsistent, and sometimes they give different answers in each session.

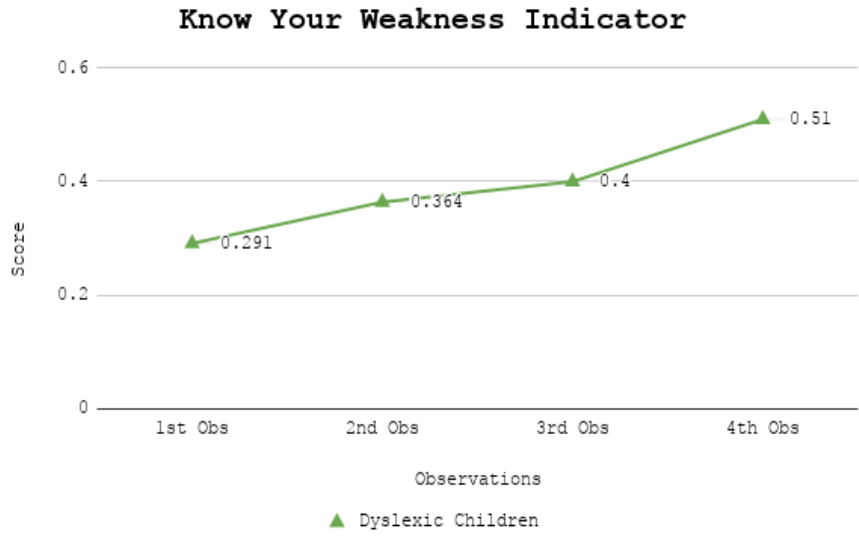

Figure 13: Average Results of Know Your Weakness Indicators Assessment

For the indicator of know your weakness, it is an indicator that is quite difficult to be mastered by children. Therefore the average increase value is small (only \pm 0.073 ) and not significant. It could be because of the inconsistency of children in answering their weaknesses in each observation session. There are constant values, some even go down, and one of them can be seen in figure 14 .

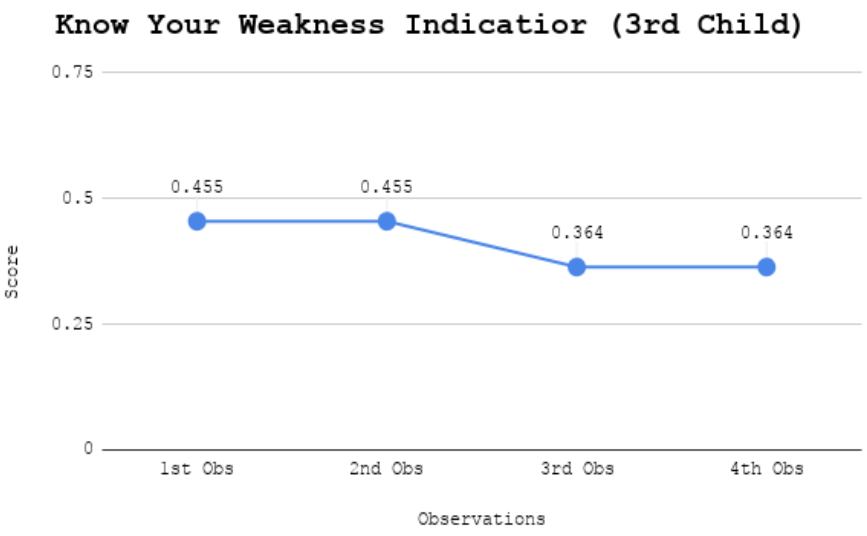

Figure 14: Assessment Result of Know Your Weakness Indicator for 3rd Child
Above is an example of a child who does not give an increase in the know your weakness indicator at each observation session. This case like on know your strength indicator, that the child still inconsistent, and sometimes he gives different answers in each session.

\section{Know Your Emotion Indicator}

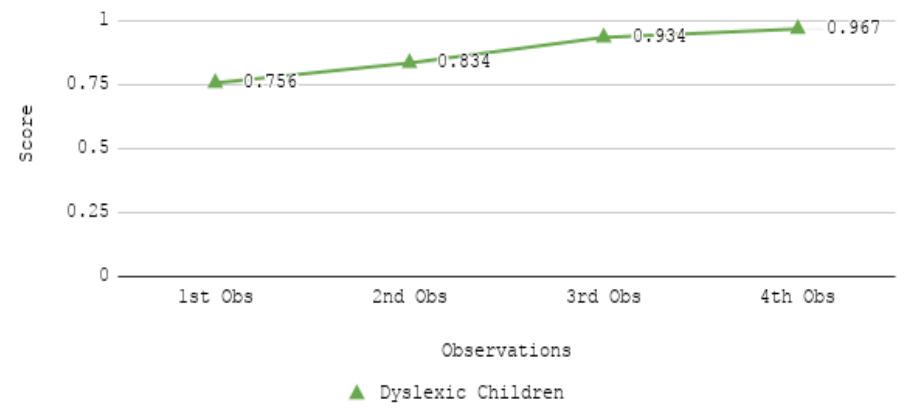

Figure 15: Average Results of Know Your Emotion Indicators Assessment

The implementation results show that the know your emotion indicator also increases for about 0.211 from the first observation 0.756 and the forth observation 0.967 as shown in figure 15 . But in this case, the psychologist data has a different state than the application, from the psychologist the increased score for about 0.067 that is from 0.668 to 0.734 . It means, the application almost states children have mastered this indicator, while psychologists say there are some points that are still not mastered by children. This can be seen in figure 16 where there are children with the same pre-test and post-test values on this indicator.

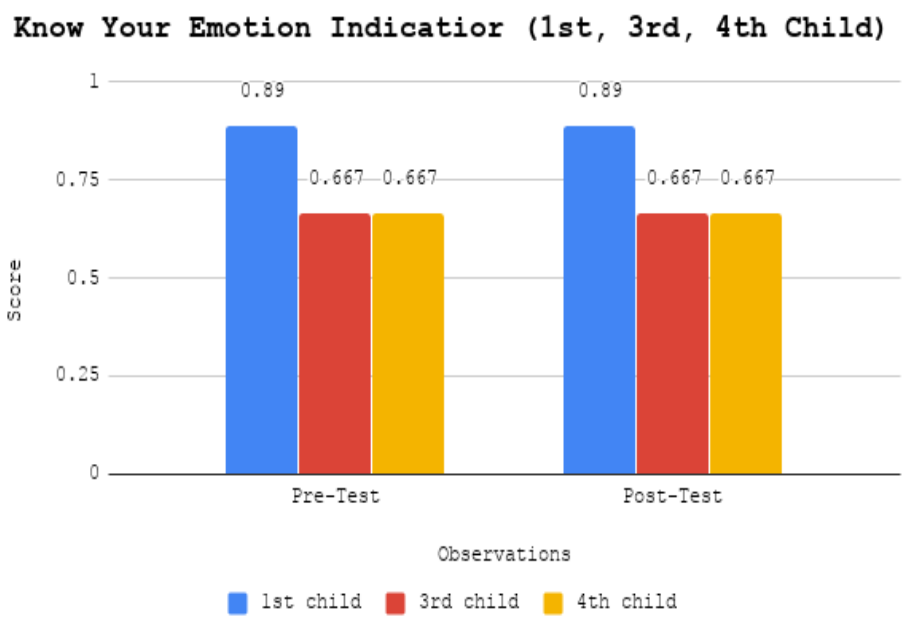

Figure 16: Assessment Result of Know Your Emotion Indicator for 1st, 3rd, and 4th Child

From all of the data, it can be concluded that the average score of rubric questionnaires given for about $10 \%$ that is from 0.668 to 0.774. A conclusion that can be derived from the data is that the data is a comparison to show an increase in self-awareness value of dyslexic children based on rubric assessment. Percent increase is not a benchmark to know the good or bad of the increase obtained. This is because this research is the first research and there is no supporting research that can be used as a reference. 


\subsection{Discussion}

Implementations conducted to identify how technology gives the influence to help dyslexic children improve their selfawareness abilities. Based on the analysis of the implementation results, there are several things that can be discussed:

1. In making applications for children with dyslexia or similar children, things that need to be considered and concluded from this research are the creation of learning content, the creation of character, making tasks for learning content and additional details that can increase children's interest in learning.

2. In the testing application that has been made, for applications with specific target users, it is recommended to go through testing and evaluation by experts. This is done to get results that are more targeted.

3. For some indicators such as know yourself and know your family, most children have mastered this indicator, even though there are children who have not mastered it, at the end of the observation session shows an improvement. This might happen because the system provides feedback when the child gives the wrong answer, so the child can be triggered to find out things that they have not been mastered. This also been proven by [8] that feedback gives positive responses thereby minimizing their mistakes.

4. For the know your strength and know your weakness indicator, it is a difficult indicator to be mastered by children. This can be seen from the inconsistency of children in answering and the results of the pre-test/post-test that did not increase significantly and some even constant.

5. For the know your emotion indicator, from the results of system usage the child has a tendency to increase selfawareness ability, but in the assessment of pre-test/post-test by psychologists this is not appropriate. Most children do not give an increase in these indicators. This might happen because they helped by the system by giving feedback so they might remember to do not make the same mistakes and be motivated to improve their answers. Besides that, the use of points and rewards can also provide encouragement and motivation during the treatment process. This is also proved by [8]. This was also done during treatment with a psychologist, they always gave feedback on their answers. But in reality children still have not mastered this ability during the research period. In traditional treatments, children usually need approximately three months to be able to make an improvement in this indicator.

6. Based on the implementation results overall CISELexia can increase the child's self-awareness state according to the average score of rubric questionnaire given for about $10 \%$ that is from 0.668 to 0.774 .

\section{Conclusion}

This study aims to design and develop an aid that can give influence in helping dyslexic children solve their emotional problems by increasing their self-awareness. In line with this the implementation results show increasing in self-awareness assessment, this can be seen from the increases average score of rubric assessment of self-awareness for about $10 \%$. It proves that children tend to improve themselves in looking for answers to things they have not mastered. It can be said that by using the CISELexia system they triggered to more curious about something. And the existence of the scoring system makes children have the motivation to improve themselves.

Overall this system still has possibilities for further improvement. Some suggestions that might be done for further research: add a variety of social story scenarios to increase data diversity in practicing know your emotion skills. It would be better to give leveling on learning emotion. Then it would be better to add a response made by the child against the social situation faced by the child to find out how far the know your emotion indicator is mastered.

\section{References}

[1] D. Bavelier, C. S. Green, and M. S. Seidenberg, "Cognitive development: gaming your way out of dyslexia?," Curr. Biol., vol. 23, no. 7, pp. R282-R283, 2013.

[2] T. Cuschieri, R. Khaled, V. E. Farrugia, H. P. Martinez, and G. N. Yannakakis, "The iLearnRW game: support for students with Dyslexia in class and at home," in 2014 6th International Conference on Games and Virtual Worlds for Serious Applications (VS-GAMES), 2014, pp. 1-2.

[3] S. M. Daud and H. Abas, "'Dyslexia Baca'Mobile App--The Learning Ecosystem for Dyslexic Children," in 2013 International Conference on Advanced Computer Science Applications and Technologies, 2013, pp. 412416.

[4] S. Franceschini, S. Gori, M. Ruffino, S. Viola, M. Molteni, and A. Facoetti, "Action video games make dyslexic children read better," Curr. Biol., vol. 23, no. 6, pp. 462-466, 2013.

[5] M. H. Raskind and E. L. Higgins, "Speaking to read: The effects of speech recognition technology on the reading and spelling performance of children with learning disabilities," Ann. Dyslexia, vol. 49, no. 1, pp. 251-281, 1999.

[6] L. Rello, C. Bayarri, and A. Gorriz, "What is wrong with this word? Dyseggxia: a game for children with dyslexia," in Proceedings of the 14th international ACM SIGACCESS conference on Computers and accessibility, 2012, pp. 219-220.

[7] L. Rello, C. Bayarri, Y. Otal, and M. Pielot, "A computer-based method to improve the spelling of children with dyslexia," in Proceedings of the 16th international ACM SIGACCESS conference on Computers \& accessibility, 2014, pp. 153-160.

[8] M. R. U. Saputra and M. Risqi, "LexiPal: Design, implementation and evaluation of gamification on learning application for dyslexia," Int. J. Comput. Appl., vol. 131, no. 7, pp. 37-43, 2015.

[9] J. P. Hourcade, N. E. Bullock-Rest, and T. E. Hansen, "Multitouch tablet applications and activities to enhance the social skills of children with autism spectrum disorders," Pers. ubiquitous Comput., vol. 16, no. 2, pp. 157-168, 2012.

[10] A. M. Piper, E. O’Brien, M. R. Morris, and T. Winograd, "SIDES: a cooperative tabletop computer game for social skills development," in Proceedings of the 2006 20th anniversary conference on Computer supported cooperative work, 2006, pp. 1-10.

[11] F. D. D. Reed, S. R. Hyman, and J. M. Hirst, "Applications of technology to teach social skills to children with autism," Res. Autism Spectr. Disord., vol. 5, no. 3, pp. 1003-1010, 2011.

[12] F. J. Sansosti and K. A. Powell-Smith, "Using computer-presented social stories and video models to increase the social communication skills of children with high-functioning autism spectrum disorders," J. Posit. Behav. Interv., vol. 10, no. 3, pp. 162-178, 2008.

[13] A. Tartaro, J. Cassell, C. Ratz, J. Lira, and V. Nanclares-Nogués, “Accessing peer social interaction: using authorable virtual peer technology as a component of a group social skills intervention program," ACM Trans. Access. Comput., vol. 6, no. 1, p. 2, 2015.

[14] J. S. K. H. E. Heiervang Anders Lund, "Behaviour problems in children with dyslexia," Nord. J. Psychiatry, vol. 55, no. 4, pp. 251-256, 2001.

[15] H. Tur-Kaspa, A. Weisel, and L. Segev, "Attributions for Feelings of Loneliness of Students with Learning Disabilities," Learn. Disabil. Res. Pract., vol. 13, no. 2, pp. 89-94, 1998.

[16] J. D. Mayer, P. Salovey, P. Salovey, and D. Sluyter, "Emotional development and emotional intelligence: Implications for educators," What is Emot. Intell., pp. 3-31, 1997.

[17] M. Narimani, A. Sadeghi, N. Homeily, and H. Siahpoosh, “A comparison of 
emotional intelligence and behavior problems in dyslexic and non-dyslexic boys," J. Appl. Sci., vol. 9, no. 7, pp. 1388-1390, 2009.

[18] D. Goleman, "Kecerdasan Emosional, terj," T. Hermaya, Jakarta Gramedia Pustaka Utama, 1996.

[19] D. Goleman, "Emotional intelligence. Why it can matter more than IQ.," Learning, vol. 24, no. 6, pp. 49-50, 1996.

[20] A. P. Association and others, "DSM: Diagnostic and Statistical Manual of Mental Disorders, VA: Arlington." 1994.

[21] A. All, E. P. N. Castellar, and J. Van Looy, "Assessing the effectiveness of digital game-based learning: Best practices," Comput. Educ., vol. 92, pp. 90103, 2016.

[22] P. Backlund and M. Hendrix, "Educational games-are they worth the effort? A literature survey of the effectiveness of serious games," in 2013 5th international conference on games and virtual worlds for serious applications (VS-GAMES), 2013, pp. 1-8.

[23] T. M. Connolly, E. A. Boyle, E. MacArthur, T. Hainey, and J. M. Boyle, "A systematic literature review of empirical evidence on computer games and serious games," Comput. Educ., vol. 59, no. 2, pp. 661-686, 2012.

[24] A. Knutas, J. Ikonen, U. Nikula, and J. Porras, "Increasing collaborative communications in a programming course with gamification: a case study," in Proceedings of the 15th International Conference on Computer Systems and Technologies, 2014, pp. 370-377.

[25] E. Tsekleves, J. Cosmas, and A. Aggoun, "Benefits, barriers and guideline recommendations for the implementation of serious games in education for stakeholders and policymakers," Br. J. Educ. Technol., vol. 47, no. 1, pp. 164-183, 2016.

[26] S. Deterding, D. Dixon, R. Khaled, and L. Nacke, "From game design elements to gamefulness: defining gamification," in Proceedings of the 15th international academic MindTrek conference: Envisioning future media environments, 2011, pp. 9-15.

[27] P. Di Bitonto, N. Corriero, E. Pesare, V. Rossano, and T. Roselli, "Training and learning in e-health using the gamification approach: the trainer interaction," in International Conference on Universal Access in HumanComputer Interaction, 2014, pp. 228-237.

[28] J. Hense, M. Klevers, M. Sailer, T. Horenburg, H. Mandl, and W. Günthner, "Using gamification to enhance staff motivation in logistics," in International Simulation and Gaming Association Conference, 2013, pp. 206-213. 